Harold Zirin, Gwaxiang Al, and Haimin Wang (eds.)

\title{
THE STATISTICAL RELATIONSHIP OF MASS MOTIONS MAGNETIC FIELDS AND FLARES IN AR 5395
}

\section{TANG YUHUA}

Department of Astronomy, Nanjing University, Nanjing 210008,China HUAN ZUNXIANG, LIN QING, XU AOAO

Department of Astronomy, Nanjing University, Nanjing 210008,China

AR 5395 was the super-active region in Solar cycle 22. In this active region, there was rapid relative motion of magnetic elements, growth and decay of umbrae, frequent newly emerging magnetic flux and various mass motions.

Data include daily vector magnetograms (Huairou Observing Station, Beijing Observatory, $\mathrm{H} \alpha$ filtergrams and photographs of sunspot group with fine structures (Yunnan Obs. and Purple Mountain Obs.) on March 9 - 15, 1989. In this period 42 flares have been observed by Yunnan and Purple Mountain Obs. (table 1). Observational data showed that all the 42 flares occurred in four segments (marked as $A, B, C, D$ ) of U-shaped neutral line in this active region (Fig. 1).

The statistical relation are studied in these four segments between daily flare weighted frequencies $Y$ (which weight at flare importance, it reflect energy level flare eruption) and dimensionless characteristic values of maximum magnetic shear $\mathrm{X} 1$, dimensionless characteristic values of maximum magnetic gradient X2 as well as newly emerging magnetic flux X3 (Fig.2). Fig. 2 shows quite poor correlation between the characteristic values of each kind in every segment with flare weighted frequencies in every segment.But it enlighten us,

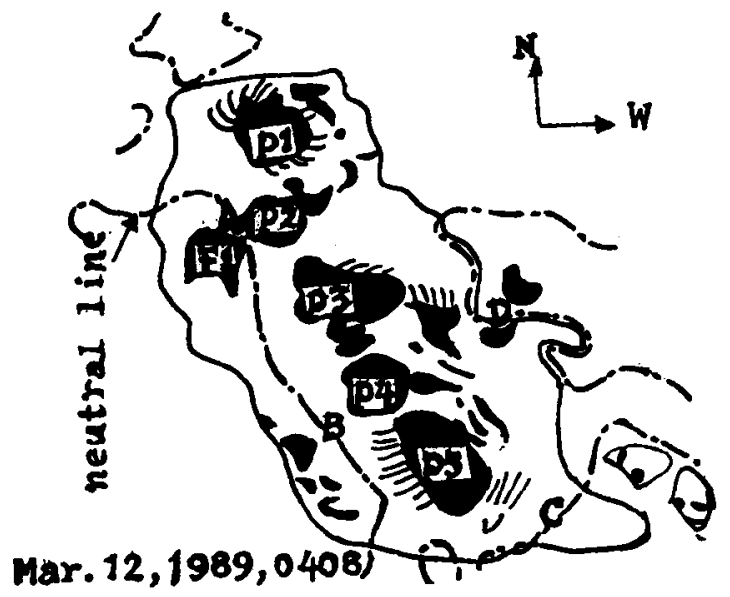

Figure 1: Four flare prolific producing segment $(A, B, C, D)$ in AR 5395 
TABLE I Statistical samples

\begin{tabular}{|c|c|c|c|c|}
\hline date & segment & $\begin{array}{l}\text { number } \\
\text { of flare }\end{array}$ & $\begin{array}{c}\text { flare-weighted } \\
\text { frequencies }\end{array}$ & $\begin{array}{c}\text { statistical samples } \\
\text { (UT) }\end{array}$ \\
\hline \multirow[t]{4}{*}{9} & A & 0 & 0 & 0 \\
\hline & B & 5 & 9.4 & $0244,0316,0458,0613,0157$ \\
\hline & $\mathrm{C}$ & 3 & 2.8 & $0408,0713,07151$ \\
\hline & D & 1 & 0.5 & 0811 \\
\hline \multirow[t]{4}{*}{10} & A & 1 & 0.5 & 0207 \\
\hline & B & 2 & 2 & 0110,0814 \\
\hline & $\mathrm{C}$ & 2 & 1 & 0238,0714 \\
\hline & D & 1 & 1.5 & 0753 \\
\hline \multirow[t]{4}{*}{11} & $\mathbf{A}$ & 1 & 0.8 & 0346 \\
\hline & B & 3 & 2.8 & $0112,0539,0308$ \\
\hline & C & 3 & 4.1 & $0149,0338,0641$ \\
\hline & D & 0 & 0 & 0 \\
\hline \multirow[t]{4}{*}{12} & $\mathbf{A}$ & 0 & 0 & 0 \\
\hline & $\mathbf{B}$ & 2 & 2.3 & 0835,0608 \\
\hline & $\mathrm{C}$ & 3 & 4.1 & $0342,0835,0531$ \\
\hline & D & 1 & 0.2 & 0704 \\
\hline \multirow[t]{4}{*}{13} & A & 0 & 0 & 0 \\
\hline & B & 1 & 3.5 & 0348 \\
\hline & $\mathrm{C}$ & 1 & 1.5 & 0148 \\
\hline & D & 1 & 1.5 & 0757 \\
\hline \multirow[t]{4}{*}{14} & A & 0 & 0 & 0 \\
\hline & B & 5 & 5.8 & $0043,0303,0626,0746,0837$ \\
\hline & $\mathrm{C}$ & 2 & 2.3 & 0918,0113 \\
\hline & $\mathrm{D}$ & 2 & 0.9 & 0433,0528 \\
\hline \multirow[t]{4}{*}{15} & A & 0 & 0 & 0 \\
\hline & B & 1 & 1.2 & 0106 \\
\hline & C & 0 & 0 & 0 \\
\hline & D & 1 & 3.8 & 0657 \\
\hline
\end{tabular}

besides the three parameters, i.e. magnetic shear, magnetic gradient and newly emerging magnetic flux, we may have to consider mass motion also, such as the spin and translational motion of the largest spot, just as Wang et al. (1991) pointed out that the motion of the largest spot played a dominant part in the active region. Therefore, we try to measure the spin angle by daily magnetogram and translational motion of the largest spot, then, consider its influence on four segments. If adding five kinds of dimensionless parameters at equally flare weighted, frequencies, synthetic active indices can be derived for every segment (marked as X). Fig.3 demonstrates the relation between X(segment) and flare weighted frequencies $Y$ (segment). One can see from Fig. 3 that there exists a linear correlation between flare weighted frequencies and synthetic indices. These results indicate that the mass motions and the magnetic fields play equal 
roles for the flare eruption. The key and the direct factor causing the flare eruptions is the enhancement of currents in an active region.

\section{REFERENCES}

1. H. Wang,F. Tang, H.Zirin and G. Ai 1991 BBSO. 0323 (submitted to Ap.J.)

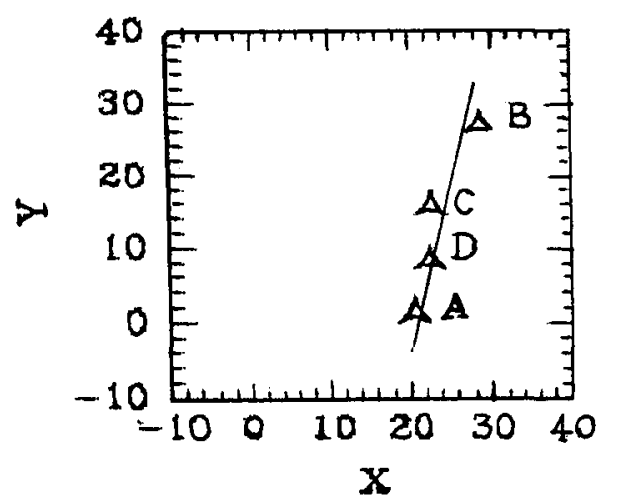

Figure 2: The relation between $\mathrm{X}$ (segment) and $\mathrm{Y}$ (segment)

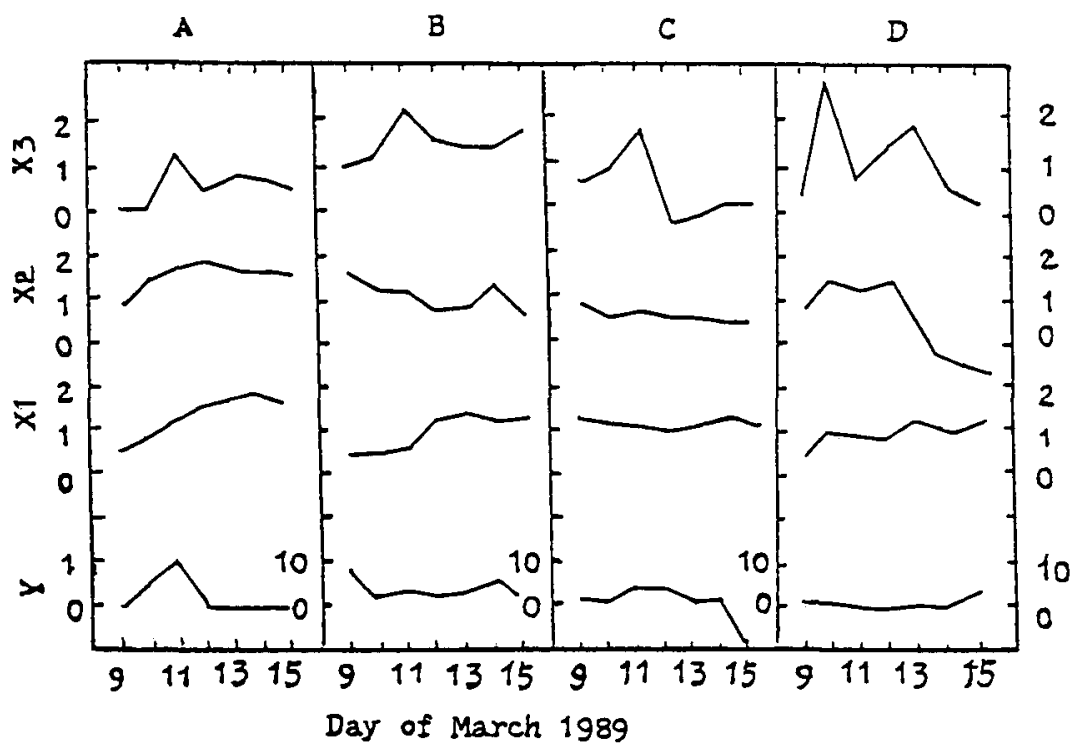

Figure 3: The relation between $\mathrm{Y}$ and $\mathrm{X} 1, \mathrm{X} 2$ as well as $\mathrm{X} 3$ in four segments 